\title{
Retraction Note: Investigation of coating delamination on steels by surface topography and Volta potential difference
}

\author{
Tongyan Pan $\cdot$ Zhaoyang Wang
}

Published online: 22 November 2014

(C) Springer-Verlag Berlin Heidelberg 2014

Retraction to: J Solid State Electrochem (2013) 17(4):1109-1115

DOI 10.1007/s10008-012-1972-4

The article "Investigation of coating delamination on steels by surface topography and Volta potential difference", published in Journal of Solid State Electrochemistry 17 (2013) 11091115 , DOI 10.1007/s10008-012-1972-4, is retracted upon request of the authors, as the article had been simultaneously submitted to and published in another journal (Pan T, "Delamination of organic coating on carbon steel studied by scanning Kelvin probe force microscopy", Surface and Interface Analysis 45 (2013) 978-984, DOI 10.1002/sia.5194).

The online version of the original article can be found at http://dx.doi.org/ 10.1007/s10008-012-1972-4.

T. Pan $(\bowtie) \cdot$ Z. Wang

The Catholic University of America, 620 Michigan Avenue, N.E,

Washington, DC 20064, USA

e-mail: pan@cua.edu

Z. Wang

e-mail:wangz@cua.edu 